\title{
Relations between resting ventricular long axis function, the electrocardiogram, and myocardial perfusion imaging in syndrome $\mathrm{X}$
}

Michael Y Henein, Giuseppe M C Rosano, Richard Underwood, Philip A Poole-Wilson, Derek G Gibson

\begin{abstract}
Objective-To investigate interrelations between ventricular long axis function, resting electrocardiogram, and myocardial perfusion imaging in a group of patients with syndrome $X$ in order to define possible underlying mechanisms.

Design-Prospective echocardiographic, electrocardiographic, and myocardial

consistently associated with absent septal q wave and abnormal myocardial perfusion imaging, while early diastolic disturbances correlated with $T$ wave abnormalities. These associations suggest that the three different investigations detect related objective abnormalities in one or more subgroups of patients with syndrome $\mathbf{X}$.
\end{abstract} perfusion imaging.

Setting-A tertiary referral centre for cardiac diseases with invasive and noninvasive facilities.

Patients-50 consecutive patients with syndrome $X$ selected on the basis of a history of angina, ST segment depression on exercise, and normal coronary arteriograms and 21 controls of similar age.

Results-Long axis motion of one or both ventricles assessed by echocardiography was abnormal in 37 patients. The onset of systolic shortening was delayed by $>130 \mathrm{~ms}$ (upper limit of normal $95 \%$ confidence interval) in eight patients, and was associated with prolonged shortening during the isovolumic relaxation period in seven ( $<<0.01$ ) (systolic abnormalities). The onset of diastolic lengthening was delayed by $>80 \mathrm{~ms}$ in 20 . Early diastolic peak lengthening rate was $<4.5 \mathrm{~cm} . \mathrm{s}^{-1}$ in 13 patients, and the relative amplitude of lengthening during atrial systole was $>45 \%$ in 18 . On the resting electrocardiogram septal q waves were absent in 12 patients. This was associated with long axis systolic disturbances in seven patients $(p<0.05)$. $T$ waves were abnormal in 10 and associated with delayed onset of early diastolic lengthening in all ( $p<0.001)$. Late diastolic long axis disturbances were not associated with any consistent electrocardiographic abnormality. Myocardial perfusion imaging was abnormal in six of 33 patients, four of whom had systolic abnormalities ( $p<$ $0.03)$. Imaging was normal in the rest, but in 13 of them long axis function was abnormal in the left side and in four it was abnormal on the right ventricle. Both electrocardiography and imaging were normal in 10 patients. No patient with an abnormal electrocardiogram or myocardial perfusion had normal long axis motion on echocardiography.

Conclusion-The function of the left and right ventricular long axes was abnormal in about $70 \%$ of a sample of patients with syndrome $X$. Systolic disturbances were
(Br Heart f 1994;71:541-547)

Syndrome $\mathrm{X}$ identifies patients who present with the clinical association of typical exertional angina pectoris, ST segment depression on exercise, and a normal coronary arteriogram. No single underlying basis has been defined. Small vessel coronary artery disease, ${ }^{1}$ coronary spasm, ${ }^{2}$ abnormal oxyhaemoglobin dissociation curve, ${ }^{3}$ and abnormal coronary vascular resistance ${ }^{4}$ have all been invoked as possible mechanisms, although none is universally accepted. The ventricular subendocardium is known to be particularly susceptible to ischaemia, and as its fibres are predominantly longitudinal in orientation, it can be studied by recording longitudinal motion of the atrioventricular rings. ${ }^{5}$ We have previously shown that in patients with documented coronary artery disease specific disturbances were present at rest and regressed with successful angioplasty. ${ }^{6}$ These include delay in the onset of shortening with respect to the $q$ wave of the electrocardiogram, prolonged shortening during isovolumic relaxation, delay in the onset of early diastolic lengthening with a reduction in its peak velocity, and an increase in the amplitude of lengthening during atrial systole. We have also shown that absence of the q wave in the lateral chest leads may be associated with similar disturbances at the onset of systole and during isovolumic relaxation. ${ }^{7}$ The aim of the present study was thus to extend these findings to patients with syndrome $X$, correlating the results with the resting electrocardiogram. We also investigated a possible relation with stress myocardial perfusion imaging, which is frequently abnormal in patients with coronary artery disease, in an attempt to determine underlying mechanisms.

Patients and methods

PATIENTS

We studied 50 consecutive patients referred for echocardiography with a mean (SD) age of 
54(8), 44 of whom were women. All fulfilled the following criteria: typical exertional angina pectoris, angiographically normal coronary arteries with no clinical evidence of coronary spasm, and an abnormal exercise electrocardiogram with at least one $\mathrm{mm}$ of horizontal or downsloping ST segment depression at peak exercise. No patient had valvar disease (including mitral valve prolapse), hypertension, cardiomyopathy, diabetes, or a history of myocardial infarction. Left ventricular hypertrophy was excluded by $M$ mode and cross sectional echocardiography. Twenty four patients $(48 \%)$ had a family history of coronary artery disease, 14 patients (28\%) smoked, and the serum cholesterol was more than $6.5 \mathrm{mmol} / \mathrm{l}$ in five. Four of the 44 women had had a hysterectomy and 20 were menopausal, defined as the absence of menstrual cycle for at least six months, oestradiol $17 \beta<100 \mathrm{pmol} / 1$, and FSH $>40 \mathrm{pmol} / 1$. All patients stopped taking cardiac medications for a week before the study. Twenty one normal subjects of mean (SD) age 51(11), 12 women, acted as controls. None had any evidence of heart disease, hypertension, or diabetes, and the routine echocardiographic indices were within the normal range in all.

\section{METHODS}

Cross sectional guided $\mathrm{M}$ mode echocardiography was performed as part of the clinical assessment on all patients and normal subjects with a Hewlett Packard sonos 1000 echocardiograph with $2.5 \mathrm{MHz}$ phased array transducer. Ventricular long axis measurements were then made with the transducer at the apex and the cursor directed to the left, septal, posterior, and right sites of the two atrioventricular rings as previously described. ${ }^{6}$

\section{Doppler}

Transmitral forward flow velocities were recorded by pulsed Doppler transducer from the apex with the cursor at the tips of mitral valve leaflets. All records were made with a simultaneous electrocardiogram (lead II) and phonocardiogram to show $\mathrm{A}_{2}$ (aortic valve closure), and were recorded photographically at a paper speed of $100 \mathrm{~mm} . \mathrm{s}^{-1}$.

\section{Electrocardiography}

A resting 12 lead electrocardiogram was recorded for each patient at $25 \mathrm{~mm} . \mathrm{s}^{-1}$ paper speed on a Hewlett-Packard electrocardiograph with a $0.05-100 \mathrm{~Hz}$ filter. The presence or absence of a $\mathrm{q}$ wave in V5 and V6 was noted. ${ }^{7}$ Abnormalities in the $\mathrm{T}$ wave were diagnosed when the amplitude was reduced $(<10 \%$ of the QRS amplitude in V6), flat, or inverted. No patient had a pathological $Q$ wave.

\section{Myocardial Scintigraphy}

Stress-Exercise stress was performed with a bicycle ergometer starting at a workload of 25 $\mathrm{W}$ and progressing in $25 \mathrm{~W}$ steps every two minutes. Heart rate and blood pressure were recorded at each stage. Thallium-201 (80
$\mathrm{MBq}$ ) was injected at peak symptom limited exercise and exercise was continued for one further minute.

Imaging - Emission tomographic imaging was begun within five minutes of the injection and redistribution imaging was performed four hours later in an identical manner. A Sopha Medical DS7 large field of view gamma camera fitted with a high resolution collimator was used. Thirty two planar images $(64 \times 64$ pixel matrix, $400 \mathrm{~mm}$ field of view, $30 \mathrm{~s}$ per image) were acquired over a $180^{\circ}$ arc from the right anterior oblique position to the left posterior oblique position. The planar images were reconstructed into transaxial tomograms of one pixel depth with back projection and Ramp-Hanning filter with a 0.75 pixel $^{-1}$ cut off frequency. From these, oblique tomograms were reorientated in the vertical long axis, horizontal long axis, and short axis planes. Images were reported by a single experienced observer blinded to the echocardiographic findings. The myocardium was divided into nine segments representing apical and basal portions of the anterior, lateral, inferior, and septal walls, together with the apex. Each segment was scored as having normal (4), mild (3), moderate (2), severely reduced (1), or absent (0) uptake. Allowance was made for established normal appearances and for attenuation from breast and other structures.

\section{Echocardiographic measurements}

The four long axis traces were digitised, ${ }^{8}$ and the following measurements were made at each site. They are similar to those that we have previously reported in coronary artery disease. ${ }^{6}$

(a) The total amplitude of ring motion, taken as the distance between peak shortening point around $A_{2}$ and peak lengthening point in late diastole at the nadir of the A wave.

(b) The time interval from the start of the $\mathrm{q}$ wave of the electrocardiogram to that of long axis shortening.

(c) The extent of further shortening after $\mathrm{A}_{2}$.

(d) The time interval from $\mathrm{A}_{2}$ to the onset of rapid early diastolic lengthening.

(e) Peak early diastolic lengthening rate.

(f) The A wave, as the extent of backward displacement of the ring after the $P$ wave on the electrocardiogram.

From the mitral Doppler trace we measured peak $E$ and $A$ velocities relative to the baseline of zero velocity and hence the $\mathrm{E}$ to $\mathrm{A}$ ratio.

Analysis of data

Long axis traces, electrocardiograms, and thallium perfusion scans were interpreted independently. Long axis scans were classified as abnormal if any one of the six measurements used was outside the corresponding normal $95 \%$ confidence interval $(95 \% \mathrm{CI})$ Bat any of the four sites. Myocardial perfusion scans were classified as abnormal if a reversible defect or increased washout was present. No patient had a fixed defect. 


\section{Statistics}

Differences between means were compared by Students $t$ test and differences in incidence by Fisher's exact probability test. The normal range was set at 2 SDs of the mean values from the normal group.

\section{Results}

\section{CLINICAL DETAILS}

Table 1 Analysis of chest pain

\begin{tabular}{lr}
\hline Characteristics & $(n)$ \\
\hline Onset: & \\
$\quad$ Rapid & 37 \\
$\quad$ Gradual & 13 \\
Location: & \\
$\quad$ Retrosternal & 48 \\
$\quad$ Left side & 2 \\
Duration (min): & \\
$5-10$ & 20 \\
$10-15$ & 12 \\
$15-30$ & 10 \\
$>30$ & 8 \\
Episodes/week: & \\
$<3$ & 6 \\
$3-7$ & 30 \\
$>7$ & 14 \\
\hline &
\end{tabular}
onset of chest pain, location, duration, and frequency of episodes. Table 2 shows details of exercise test results including heart rate and range of ST segment depression.

\section{LONG AXIS}

Figure 1 shows a normal long axis trace. Tables 3 and 4 show values for each of the four sites from the control group. The overall pattern of motion was the same in all. During

Table 2 Analysis of exercise test
Table 1 shows patients, symptoms including changes, blood pressure, exercise duration,

\begin{tabular}{lc}
\hline Variables & Mean (SD) \\
\hline Resting heart rate(beats/min) & $77(20)$ \\
Peak heart rate (beats/min) & $150(20)$ \\
Peak blood pressure (mm Hg) & $160(25)$ \\
Range of ST depression (mm) & $1-3.6$ \\
Exercise duration (s) & $510(190)$ \\
\hline
\end{tabular}

Table 3 Normal mitral Doppler values and long axis dimensions

\begin{tabular}{ll}
\hline Variables & Controls (mean $(S D))$ \\
\hline Mitral Doppler: & \\
E wave velocity $(\mathrm{m} / \mathrm{s})$ & $0 \cdot 7(0 \cdot 1)$ \\
A wave velocity $(\mathrm{m} / \mathrm{s})$ & $0 \cdot 5(0 \cdot 1)$ \\
E/A ratio & $1 \cdot 4(0 \cdot 4)$ \\
Left: & \\
$\quad$ Total excursion $(\mathrm{cm})$ & $1 \cdot 5(0 \cdot 3)$ \\
Atrial systole $(\mathrm{cm})$ & $0 \cdot 4(0 \cdot 1)$ \\
Septal: & \\
Total excursion $(\mathrm{cm})$ & $1.5(0 \cdot 4)$ \\
Atrial systole $(\mathrm{cm})$ & $0 \cdot 5(0 \cdot 2)$ \\
Right: & \\
Total excursion $(\mathrm{cm})$ & $2 \cdot 6(0 \cdot 3)$ \\
Atrial systole $(\mathrm{cm})$ & $0.9(0 \cdot 1)$ \\
Posterior: & \\
Total excursion $(\mathrm{cm})$ & $1 \cdot 6(0 \cdot 2)$ \\
Atrial systole $(\mathrm{cm})$ & $0 \cdot 6(0 \cdot 1)$ \\
\hline
\end{tabular}

Table 4 Normal long axis timing and peak lengthening rates

\begin{tabular}{ll}
\hline Variables & Controls (mean $(S D))$ \\
\hline Left: & $90(19)$ \\
Q to onset of shortening $(\mathrm{ms})$ & $58(11)$ \\
$\mathrm{A}_{2}$ to onset of lengthening $(\mathrm{ms})$ & $10(2 \cdot 5)$ \\
Peak lengthening rate $(\mathrm{cm} / \mathrm{s})$ & \\
Septal: & $81(9)$ \\
$Q$ to onset of shortening $(\mathrm{ms})$ & $60(9)$ \\
$\mathrm{A}_{2}$ to onset of lengthening $(\mathrm{ms})$ & $6 \cdot 5(1)$ \\
Peak lengthening rate $(\mathrm{cm} / \mathrm{s})$ & \\
Right: & $95(20)$ \\
Q to onset of shortening $(\mathrm{ms})$ & $11(20)$ \\
$\mathrm{A}_{2}$ to onset of lengthening $(\mathrm{ms})$ & $10(2 \cdot 5)$ \\
Peak lengthening rate $(\mathrm{cm} / \mathrm{s})$ & \\
Posterior: & $100(13)$ \\
$Q$ to onset of shortening $(\mathrm{ms})$ & $65(10)$ \\
$\mathrm{A}_{2}$ to onset of lengthening $(\mathrm{ms})$ & $9(1 \cdot 5)$ \\
Peak lengthening rate $(\mathrm{cm} / \mathrm{s})$ & \\
\hline
\end{tabular}
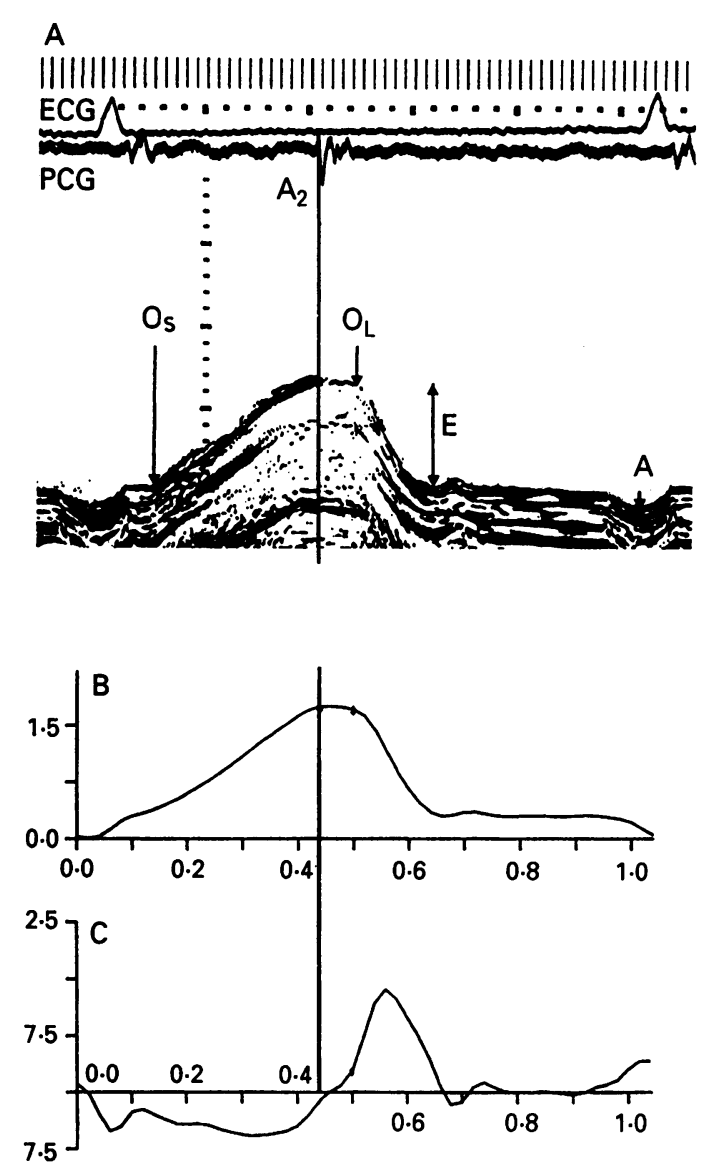

Figure 1 (A) normal long axis $M$ mode recording of the left site of the mitral ring showing normal longitudinal motion in relation to different phases of cardiac cycle. (B) digitised normal trace. (C) Rate of change showing early diastolic peak lengthening rate. ECG, electrocardiogram; $P C G$, phonocardiogram; $O_{s}$, onset of shortening; $O_{L}$, onset of lengthening.

ejection the long axis shortens as the atrioventricular rings move towards the apex of the left and right ventricles. Peak shortening is almost synchronous with $\mathrm{A}_{2}$. Diastolic lengthening occurs during early diastole and atrial systole with a period of diastasis interposing when heart rate is slow (fig 1 ).

PATIENTS

Overall amplitude of motion was normal in all patients at all four sites, and in 37 patients two or more of the remaining measurements were outside the normal range (fig 2).

(a) In eight patients, the onset of long axis shortening, with respect to the $q$ wave of the electrocardiogram, was delayed in one or more segments. Further longitudinal shortening of $>1 \mathrm{~mm}$ occurred during isovolumic relaxation in seven. The two abnormalities occurred together in four patients, and this association was very significant $(p<0.01)$. We therefore considered these two disturbances together and refer to them as "systolic" abnormalities.

(b) In 20 patients the onset of long axis lengthening was delayed by more than $80 \mathrm{~ms}$ after $\mathrm{A}_{2}$ (aortic valve closure), although further inward movement did not occur. Six of these also had delayed onset of shortening, no more than would be expected by chance (NS). 
Table 5 Incidence of segmental long axis abnormalities

\begin{tabular}{lcccccc}
\hline & $\begin{array}{l}\text { Septal } \\
(n)\end{array}$ & $\begin{array}{l}\text { Left } \\
(n)\end{array}$ & $\begin{array}{l}\text { Posterior } \\
(n)\end{array}$ & $\begin{array}{l}\text { Left } \\
\text { ventricle } \\
(\%)\end{array}$ & $\begin{array}{l}\text { Right } \\
(n)\end{array}$ & $\begin{array}{l}\text { Right } \\
\text { ventricle } \\
(\%)\end{array}$ \\
\hline Systolic & 9 & 14 & 13 & 27 & 3 & 6 \\
A to onset of lengthening & 12 & 20 & 14 & 34 & 7 & 14 \\
Peak lengthening rate & 11 & 4 & 3 & 7 & 10 & 20 \\
A wave & 22 & 10 & 3 & 13 & 9 & 18 \\
\hline
\end{tabular}

(c) Early diastolic peak lengthening rate was reduced to $<4.5 \mathrm{~cm} . \mathrm{s}^{-1}$ in 13 , and relative long axis excursion during atrial systole was $>45 \%$ in 18 patients. The three diastolic abnormalities, delayed onset of lengthening, reduced peak lengthening rate, and increased relative atrial contraction often overlapped (fig 3).

Analysis of the different segments affected in the left and right ventricles (table 5) showed that delayed onset of shortening, prolonged inward motion during isovolumic relaxation, and delayed onset of lengthening all occurred more commonly in the left ventricular sites, whereas late diastolic abnormalities were more common on the right.

A

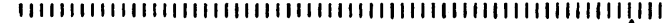
ECG

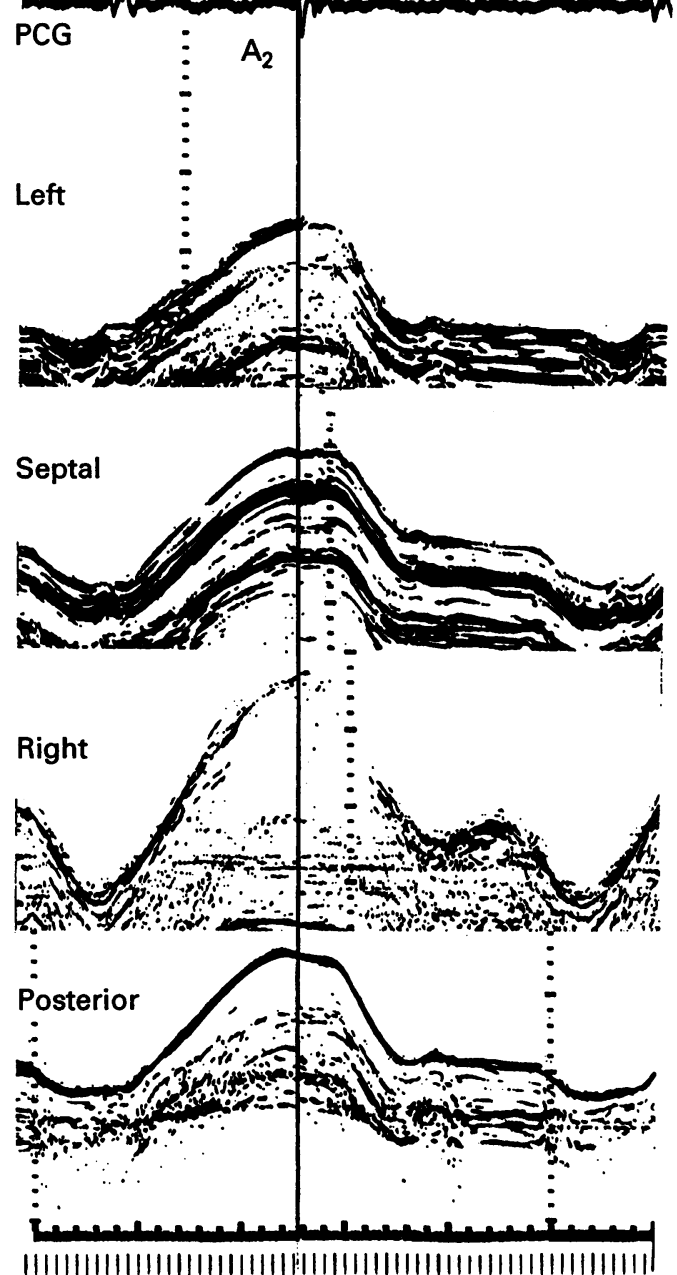

COMPARISON BETWEEN LONG AXIS FINDINGS AND RESTING ELECTROCARDIOGRAM

In 13 patients an electrocardiogram and long axis trace were both normal, and in 25 both were abnormal, the electrocardiogram showed absent septal $q$ waves or $T$ wave changes. In the remaining 12 patients the long axis trace showed more than one abnormality although the resting electrocardiogram was normal. No patient had an abnormal electrocardiogram and a normal long axis trace. This association between any abnormality of the long axis trace and any abnormality of the electrocardiogram was very significant $(p<0.001)$. Of the 12 cases with an abnormal long axis trace but a normal electrocardiogram, abnormalities were confined to the right side in four, and in the rest the dominant disturbance was an increase in the atrial component.

Further analysis of these interrelations showed absence of the septal $\mathrm{q}$ wave in the lateral chest leads in 12 cases and its presence in 38. Seven of those with absent septal $\mathrm{q}$ wave had a systolic abnormality, delayed onset of shortening in four, and abnormal shortening during isovolumic relaxation in

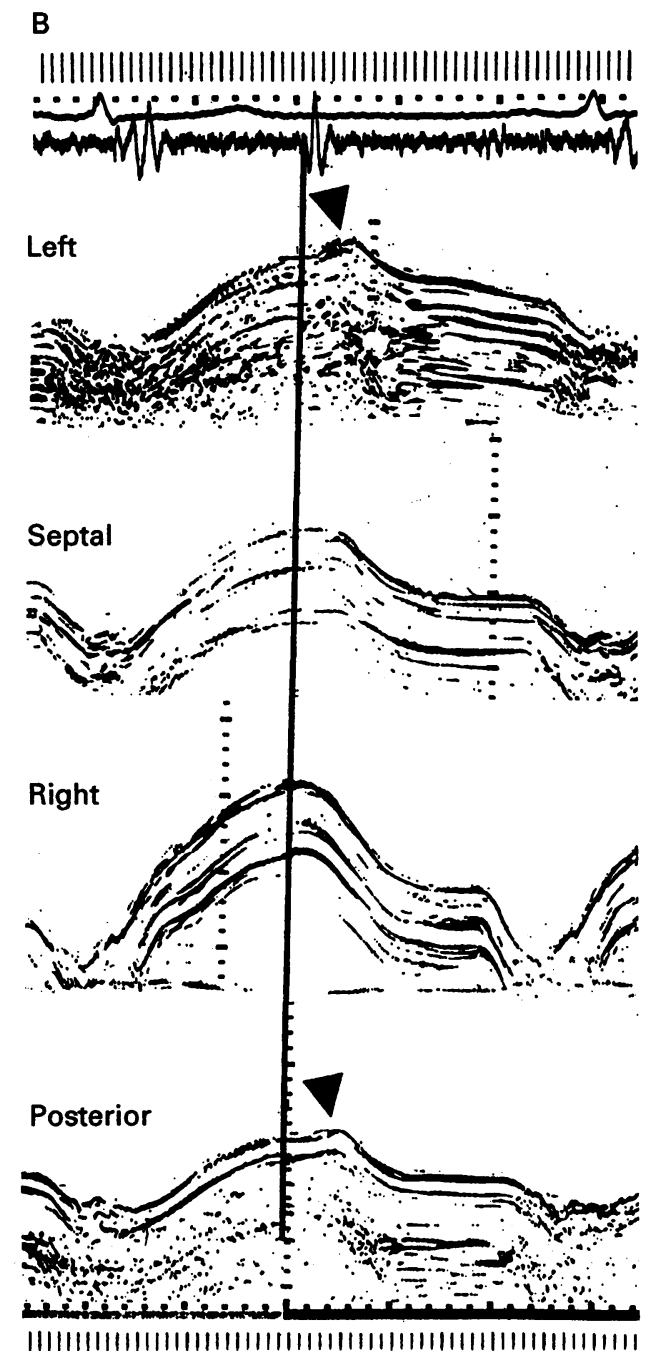

Figure 2 Long axis $M$ mode recordings of the left, septal, right, and posterior sites of the atrioventricular rings taken from (A) a normal subject and $(B)$ a patient with syndrome $X$. Note the abnormal prolonged shortening during isovolumic relaxation at the left and posterior sites (arrows). Both were recorded with a simultaneous electrocardiogram and phonocardiogram. Vertical line represents $A_{2}$ (aortic valve closure). 


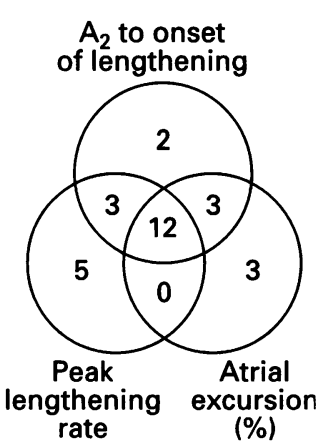

Figure 3 Venn diagram illustrates the overlap between the three diastolic abnormalities of left ventricular long axis function. The number of cases in each of the groups and the degree of overlap is indicated. three, a significant association $(p<0.05)$. The lateral $T$ waves were normal in 40 patients but abnormal in 10, all of whom had an increase in the time interval from $\mathrm{A}_{2}$ to the onset of lengthening. Delayed lengthening was also present in a further 10 patients in whom $T$ wave morphology was normal. The interval from $A_{2}$ to the onset of lengthening and $T$ waves were both normal in 30 patients, so that the overall association between these two disturbances was very significant $(p<$ $0.001)$.

\section{LONG AXIS FUNCTION AND MYOCARDIAL PERFUSION IMAGING}

Thirty three patients underwent myocardial perfusion imaging. Perfusion and long axis function were both normal in 10 , and both abnormal in six. Two of the abnormal perfusion scans showed significant reversible defects and the rest had clear areas of increased washout. Four patients of these six had a systolic abnormality at one of the left ventricular sites, a significant association $(p<$ 0.03 ). In the remaining 17 patients long axis function was abnormal on the left side in 13, confined to the right in four, but the myocardial perfusion scan was normal. The presence of an abnormal myocardial perfusion image was not related to the extent of ST depression in the treadmill exercise test, or to the resting electrocardiogram. No patient with abnormal myocardial perfusion had normal long axis function.

\section{MITRAL DOPPLER}

In three patients there was a summation flow pattern, and in the rest separate $E$ and $A$ waves could be identified. The peak $E$ wave was reduced in 15 patients, and $A$ wave velocity abnormally increased in 10 . The $E$ to $A$ ratio was $<0.6$ (the lower limit of the normal $95 \%$ CI) in only one patient. None of these values related to the presence or absence of a myocardial perfusion defect or an electrocardiographic abnormality.

\section{Discussion}

The basis of syndrome $\mathrm{X}$ is still uncertain, but there is suggestive evidence that myocardial ischaemia may occur with stress, although epicardial coronary arteries are normal. ${ }^{9}$ Anginal pain, ST segment depression, lactate production, ${ }^{10}$ and thallium perfusion defects $^{11-14}$ are all compatible with this explanation. We have recently shown that left ventricular long axis function may be disturbed under resting conditions in patients with coronary artery disease, and that these abnormalities regress after successful angioplasty. ${ }^{6}$ Unlike coronary artery disease, there is no agreed objective standard of comparison in syndrome $\mathrm{X}$ against which the diagnostic accuracy of a new test can be compared. We therefore correlated our results with the resting electrocardiogram and myocardial perfusion imaging, both of which are abnormal in a proportion of patients with this condition. A positive correlation would not, of course, have the same diagnostic significance as it would against an abnormal coronary arteriogram, but might instead point to new interrelations between the different manifestations of syndrome $\mathrm{X}$, and thereby shed light on basic mechanisms.

We found that long axis function is indeed abnormal in about two thirds of a sample of patients with syndrome $\mathrm{X}$. These disturbances were similar to but less than those seen in coronary artery disease. They affected the long axis and were both systolic and diastolic in timing. Most commonly they involved the onset of early diastolic lengthening and the extent of overall lengthening that occurred during atrial systole. Less often, the onset of inward motion with respect to the $q$ wave of the electrocardiogram was delayed, with further shortening during isovolumic relaxation. Early diastolic lengthening velocity was also reduced. As in coronary artery disease, these different disturbances did not occur randomly, but tended to be segregated. Thus delayed onset of shortening and further abnormal shortening during isovolumic relaxation occurred together, as did delay in the onset of lengthening with respect to $A_{2}$ and disturbances of later diastole: reduced lengthening rate, and an increased atrial component. The number of long axis sites involved varied considerably, and in a few patients only the right side was affected.

$T$ wave abnormalities have long been well recognised in syndrome $X .{ }^{15}$ They are often to be found in the inferior or lateral leads, although there is no consensus as to their origin or significance. They were present in 10 of our patients, all of whom had delayed onset of long axis lengthening in one or more of the left ventricular long axis sites, a highly significant association $(p<0.001)$. Although such delay often occurs along with abnormal motion later in diastole, the peak lengthening rate being reduced or the atrial component increased, in no case were these two disturbances, either singly or in combination, associated with abnormal $\mathrm{T}$ waves. A less widely recognised disturbance in our patients was loss of the normal septal $q$ wave in the lateral chest leads. This abnormality is well known to occur in the presence of left sided conduction disturbances, and indeed is one of the main criteria for differentiating left bundle branch block from interventricular conduction delay. Isolated loss of septal $\mathrm{q}$ wave was described in 150 patients by Burch and DePasquale, who suggested an association with septal fibrosis, although they did not document this in any detail. ${ }^{16}$

More recently, we have found in a group of patients with structurally normal hearts but a variety of cardiac diagnoses, that absence of the septal q wave was associated with a delay in the onset of long axis shortening, usually involving the septum, frequently with further abnormal shortening during isovolumic relaxation. ${ }^{7}$ Our present results are thus compatible with these previous findings and extend the association to patients with syndrome $\mathrm{X}$. It was therefore suggestive that the same dis- 
turbance of long axis function was correlated with abnormal myocardial perfusion imaging although the incidence of this was low in the group of patients we studied.

Our results are thus further evidence of an objective abnormality occurring in at least some patients with the diagnosis of syndrome $\mathrm{X}$. They seem to provide a link between three different types of disturbance: electrophysiological, wall motion, and myocardial perfusion. They reflect widely different aspects of myocardial physiology, and the methods used to detect them are quite different in their physical basis. Also, it was possible to identify several types of disturbance within the general diagnosis of syndrome $\mathrm{X}$. Firstly, was the association between delayed onset of shortening, loss of the septal q wave, and an abnormal myocardial perfusion scan. Secondly, the onset of early diastolic long axis lengthening with lateral $T$ wave changes was delayed. Thirdly, long axis abnormalities of later diastole or any affecting the right ventricle alone, were never on their own associated with either electrocardiographic or perfusion abnormality.

These associations do not provide an explanation for syndrome $X$. Nevertheless, recognising a pattern may be a step towards defining a mechanism. Long axis function is supported mainly by subendocardial fibres. Not only are these particularly susceptible to ischaemia, but also the subendocardium of the septum is the first part of the left ventricle to show mechanical activity after normal activation. ${ }^{17}$ Segmental delay in long axis function might thus be expected when the septal $\mathrm{q}$ wave is lost. Similarly, the genesis of $T$ wave changes on the resting electrocardiogram is ill understood, but it may have been significant that the one long axis abnormality correlating with them was that which was almost synchronous with the $T$ wave in the cardiac cycle. It may be that the resting abnormalities of long axis function that we found were the long-term result of previous attacks of ischaemia, induced by some independent mechanism. Alternatively it is possible that rather than being the result of ischaemia, they contributed to its cause. Maximum coronary flow velocities occur early in diastole. ${ }^{18}$ Regional myocardial tension persisting at this time might therefore be expected to reduce local flow, particularly during tachycardia when diastolic time is short. The two disturbances most closely associated with perfusion disturbances were those that prolong the development of tension during isovolumic relaxation, whereas those later in diastole, such as a reduced peak lengthening rate or an increase in the atrial component, had no such effect.

The association of myocardial ischaemia with such a low incidence of abnormal myocardial perfusion is, at first sight, difficult to explain. This would certainly be the case if the ischaemia were transmural. If, however, the resulting ischaemia were confined to the subendocardium, the low incidence of perfusion abnormalities associated with ST seg- ment depression would be explained. Our conclusions are also apparently inconsistent with those of a previous echocardiographic study that failed to show regional wall motion abnormalities during exercise in patients with syndrome X. ${ }^{19}$ Cross sectional stress echocardiography depends on the subjective appreciation of systolic wall motion. As ischaemia develops systolic disturbances develop later than diastolic, so with a repetition rate of $\leqslant 30$ per second cross sectional echocardiography would be incapable of showing the disturbances in the timing rather than the amplitude of wall motion. Our conclusions depend upon recognition of timing disturbances and the $M$ mode approach is well adapted to displaying them. Again, if the ischaemia were confined to the subendocardium, the resulting disturbances of systolic wall motion would be subtle, and almost certainly not detectable from subjective inspection of cross sectional images.

The reported incidence of abnormalities detected by thallium imaging in patients with syndrome $\mathrm{X}$ varies. Tweddel and colleagues found abnormalities in 98 of 100 patients with chest pain and a normal coronary arteriogram, ${ }^{14}$ whereas Legrand and colleagues found abnormalities in three of $18 .^{20}$ In both of these studies patients were referred for arteriography on the basis of perfusion abnormalities and so the populations are not equivalent to our own. Also, the planar imaging used in previous studies has a reduced specificity compared with emission tomography for the detection of regional perfusion abnormalities in coronary artery disease. ${ }^{21}$

Although our results do not identify a single specific mechanism underlying syndrome $\mathrm{X}$, they extend previous findings. Disturbances occur in a region of myocardium known to be particularly sensitive to ischaemia, and their presence correlates with electrocardiographic and perfusion defects. They are similar to those seen in patients with coronary artery diseases that are known to be at least partly reversible by angioplasty. Their varying interrelation with the electrocardiogram and myocardial perfusion imaging suggests that a group of disturbances might be involved rather than a single homogenous condition.

1 Mosseri M, Yarom R, Gotsman MS, Hasin Y. Histologic evidence for small-vessel coronary artery disease in patients with angina pectoris and patent large coronary arteries. Circulation 1986;74:964-72.

2 Maseri A, Crea, F, Kaski JC, Crake T. Mechanisms of angina pectoris in syndrome X. $\mathcal{F}$ Am Coll Cardiol 1991; 17:499-506.

3 Chierchia S, Lazzari M, Freedman B, Brunelli C, Maseri A. Impairment of myocardial perfusion and function A. Impairment of mocardial perfusion and function during painless

4 Kaski JC, Tousoulis D, Galassi AR, McFadden E, Pereira WI, Crea F, Maseri A. Epicardial coronary artery tone and reactivity in patients with normal coronary arterioand reactivity in patients with normal coronary arteriograms and reduced coronary Cardiol 1991:18:50-4.

5 Jones CJH, Raposo L, Gibson DG. Functional importance of $\mathrm{CJH}$, Raposo L, Gibson DG. Functional importance of the long axis dynamics

6 Henein MY, Priestly K, Davarashvili T, Buller N, Gibson DG. Improved left ventricular subendocardial function following successful coronary angioplasty. Br Heart $\mathcal{F}$ 1993;69:501-6. 
7 Xiao HB, Brecker SJ, Henein MY, Jin XY, Gibson DG. Absent septal q waves: an unrecognised hallmark of the effects of abnormal activation pattern on left ventricular diastolic function. Circulation 1993;88(suppl):I-346.

8 Gibson DG, Brown D. Measurement of instantaneous left ventricular dimension and filling rate in man, using echocardiography, Br Heart $¥$ 1973;35:1141-9.

9 Kaul S, Newell JB, Chesler DA, Pohost GM, Okada RD, Boucher CA. Quantitative thallium imaging findings in patients with normal coronary angiographic findings and in clinically normal subjects. Am $\mathcal{F}$ Cardiol 1986;57: 509-12.

10 Boudoulas H, Cobb TC, Leighton RF, Wilt SM. Myocardial lactate production in patients with angina like chest pain and angiographically normal coronary arteries and left ventricle. Am $\mathcal{f}$ Cardiol 1974;34:501-5.

11 Beller GA. Diagnostic accuracy of Thallium-201 myocardial perfusion imaging. Circulation 1991;84:I.1-6.

12 Berger BC, Abramowitz R, Park CH, Desai AG, Madsen MT, Chung EK, Brest AN. Abnormal thallium-201 scans in patients with chest pain and angiographically normal coronary arteries. $A m$ f Cardiol 1983;52:365-70.

13 Meller J, Goldsmith SJ, Rudin A, et al. Spectrum of exercise thallium-201 myocardial perfusion imaging in patients with chest pain and normal coronary angiograms. $A m \mathcal{F}$ with chest pain and norm
Cardiol $1979 ; 43: 717-23$.

14 Tweddel AC, Martin W, Hutton I. Thallium scans in syndrome X. Br Heart $\mathcal{F}$ 1992;68:48-50.
15 Kemp HG, Vokonas PS, Cohn PF, Gorlin R. The anginal syndrome associated with normal coronary arteriograms. Am 7 Med 1973;54:735-42.

16 Burch GE, DePasquale N. A study at autopsy of the relation of absence of the q wave in lead I, avL, V5 and V6 to tion of absence of the q wave in lead l, avL,

17 Durrer D, van Dam RT, Freud GE, Janse MJ, Meijler FL Arzbaecher RC. Total excitation of the isolated human Arzbaecher RC. Total excitation of

18 Cobbe SM. Coronary blood flow and myocardial ischaemia. In: Julian DG, Camm AJ, Fox KM, et al, eds. Disease of the heart. 1st ed. London: Bailliere Tindall, 1989:1085-102.

19 Nihoyannopoulos P, Kaski JC, Crake T, Maseri A. Absence of myocardial dysfunction during stress in patients with syndrome X. $\mathcal{F}$ Am Coll Cardiol 1991;18: 1463-70.

20 Legrand V, Hodgson JMcB, Bates ER, et al. Abnormal coronary flow reserve and abnormal radionuclide exercise test results in patients with normal coronary angiograms. F Am Coll Cardiol 1985;6:1245-53.

21 Fintel DA, Links JM, Brinker JA, Frank TL Parker M Becker LC. Improved diastolic performance of thallium 201 single photon emission computed tomo pol single photon ever planar imaging in the diagnosis of coronary artery Coll Cardiol 1989;13:600-12. 